\title{
Traumatic Urethrovaginal Fistula from Female Genital Mutilation Presenting as Bladder Outlet Obstruction: A Rare Case Report
}

\author{
Abubakar Sadiq Muhammad ${ }^{1,2 *}$ and Solomon Marcus ${ }^{2}$ \\ ${ }^{1}$ Urology Unit, Department of Surgery, Usmanu Danfodiyo University Teaching Hospital Sokoto, Nigeria \\ ${ }^{2}$ Urology Unit, Department of Surgery, Federal Medical Centre Gusau, Zamfara State, Nigeria
}

*Corresponding author: Dr. Abubakar Sadiq Muhammad, Urology Unit, Department of Surgery, Usmanu Danfodiyo University Teaching Hospital Sokoto, Nigeria.

Received Date: June 18,2021

Published Date: July 08,2021

\begin{abstract}
Background

Urethrovaginal fistula is an abnormal communication between urethra and vagina by an epithelialized tract. In girls the cause can be congenital or post traumatic. Female genital mutilation may be associated with urethrovaginal fistula and the predominant presentation is that of continuous urinary incontinence. Presentation with bladder outlet obstruction and inability to pass urine is rare. We report a 12-year old girl with traumatic urethro-vaginal fistula post female genital mutilation who presented with inability to pass urine and bladder outlet obstruction.

\section{Case report}

This is a 12-year old girl who presented with urethral bleeding and inability to pass urine following female genital mutilation. She had suprapubic cystostomy due to failed urethral catheterization. Micturating cystourethrogram revealed huge bladder with tight bladder neck. The haemogram, urine microscopy, electrolyte urea and creatinine were within normal limits. She had examination under anaesthesia which revealed urethrovaginal fistula and obliteration of the bladder neck. She had multilayer repair of the fistula via abdominoperineal approach. Urethral catheter was removed after 6 weeks. She developed nocturnal enuresis post operatively which was managed with tolterodine.

\section{Conclusion}

Urethrovaginal fistula from female genital mutilation may present with bladder outlet obstruction. Micturating cystogram may not be diagnostic. Examination under anaesthesia may be necessary for proper diagnosis. Abdominoperineal multilayer repair is associated with good outcome.

Key words: Urethrovaginal fistula, Female genital mutilation, Bladder outlet obstruction, Multilayer repair.

Abbreviations: FC: Female circumcision; UVF: Urethrovaginal fistula; FGM: Female Genital Mutilation; WHO: World Health Organization; NG Tube: Naso Gastric Tube; EUA: Examination under anaesthesia.

\section{Introduction}

Urethrovaginal fistula (UVF) is a communication between the urethra and vagina by an epithelialized tract [1]. In girls it can be congenital or post traumatic [1]. In adult it may be sequelae of prolonged obstructed labour in developing countries [2], while in developed countries it is iatrogenic from transvaginal surgeries [3,4]. Female Circumcision (FC)or Female Genital
Mutilation (FGM) is a common cause of UVF in developing countries [5]. FGM is defined by World Health Organization (WHO) as partial or total removal of female external genitalia or other injury to female genital organs for non- medical reasons [6]. It is carried out in young girls below the age of 15 years including infants [6]. The prevalence of FGM in Nigeria among women is $41 \%$ but the 
prevalence is declining in young girls [5]. The practice is believed to prepare the girls for adulthood, marriage by preserving virginity, improving chastity and fertility [5]. Three million girls are at risk and more than two hundred (200) million girls and women have undergone FGM globally [5,7]. Studies in Sub-Saharan African showed relationship between FGM, poverty and illiteracy $[8,9]$. Female genital mutilation is associated with short term and longterm complications [10]. Short term complications include pain, hemorrhage, transmission of infections, shock and death [10]. Long term complications include female sexual dysfunctions, urinary, gynecological and obstetric complications [10]. Urogynaecological complications include urethrovaginal and vesicovaginal fistulae. These present with continous urinary incontinence [3]. Early presentation with acute urinary retention, and bladder outlet obstruction masking urethrovaginal fistula is rare. There are few reports of urethrovaginal fistula from FGM and none presented with bladder outlet obstruction [11]. We report a case of a 12-year-old girl who presented with bladder outlet obstruction masking traumatic ure- throvaginal fistula from female genital mutilation

\section{Case presentation}

This is a 12-year old girl who presented with 24 hours history of urethral bleeding, inability to pass urine and suprapubic pain following incision in the external genitalia by a local barber. No previous history of lower urinary tract symptoms or trauma. She had no comorbidity. She was in painful distress, afebrile, not pale, anicteric acyanosed. The vital signs were normal. The urinary bladder was palpable and tender. There was blood at the introitus and longitudinal incision involving urethra, clitoris and labia minora. Diagnosis of acute urinary retention secondary to female genital mutilation was made. Attempt at urethral catheterization with size 8 and 10 Foley's catheter failed for which she had suprapubic cystostomy. Trial of voiding per urethra at 11 weeks post injury was done and the patient was unable to pass urine. Micturating cystourethrogram revealed huge urinary bladder with outpouching of the fundus and closed bladder neck (Figure 1).

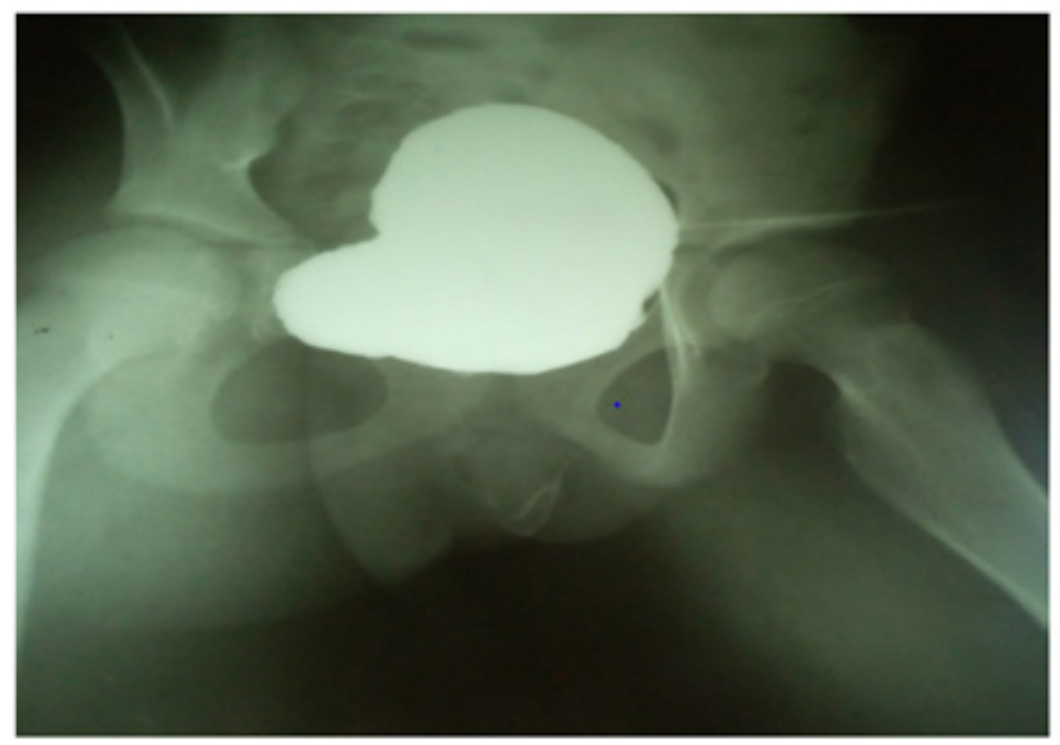

Figure 1: Micturating cystourethrogram showing huge urinary bladder with outpouching of the fundus and closed bladder neck.

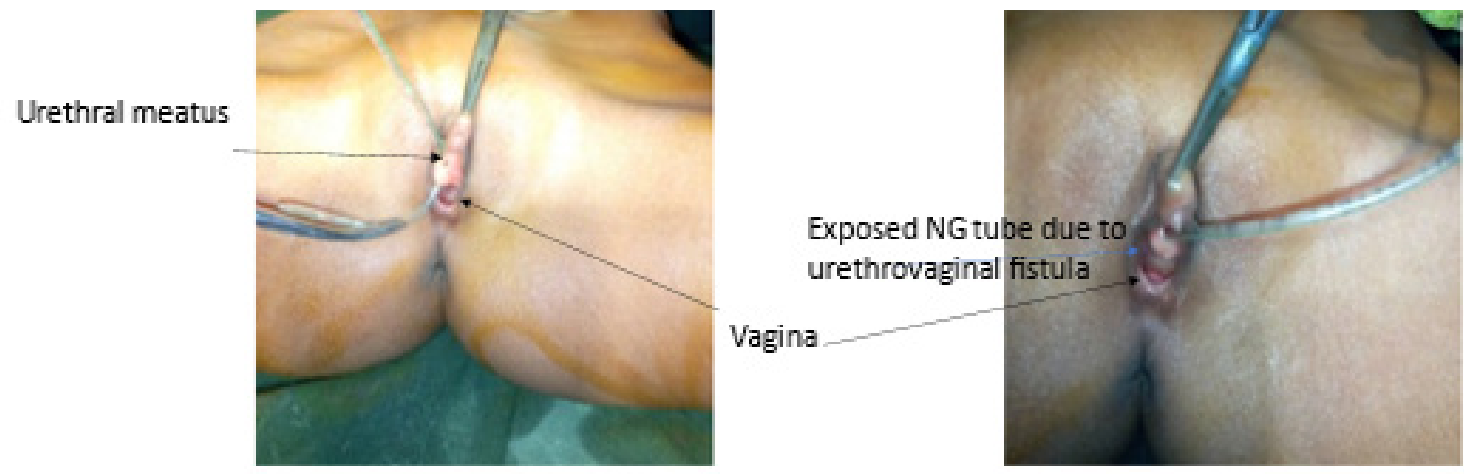

Figure 2: EUA picture showing the urethrovaginal fistula with an indwelling stent passing through the vagina(a) and proximal urethra(b). 
Electrolyte urea and creatinine were normal. Urine microscopy showed no growth. Haemogram was $10 \mathrm{mg} / \mathrm{dl}$, white blood cell count was $9 \times 109 / \mathrm{L}$, platelet count was $443 \times 109$. Urinary bladder was thickened with mobile internal echoes. She had examination under anaesthesia (EUA) in lithotomy position 8 weeks post FGM which revealed $2 \mathrm{~cm}$ urethrovaginal fistula $2 \mathrm{~cm}$ from the external urethral meatus, fibrosis of the surrounding tissues and complete obliteration of the proximal urethra/bladder neck opening by a mucosal web (Figure 2) via abdominoperineal approach continuity was established between the bladder neck and proximal urethra. Multilayer repair of the urethrovaginal fistula was done over a $10 \mathrm{Fr}$ silicon catheter as stent (Figure $3 \mathrm{a} \& \mathrm{~b}$ ). Suprapubic cystostomy was inserted using 18Fr Foley's catheter. Urethral stent was removed after 6 weeks and trial of voiding was satisfactory. Suprapubic catheter was subsequently removed. She developed irritative lower urinary symptoms and enuresis which were treated with tolterodine. The vaginal examination done 8 weeks post-operatively was normal and Marshall's test was negative (Figure 4).
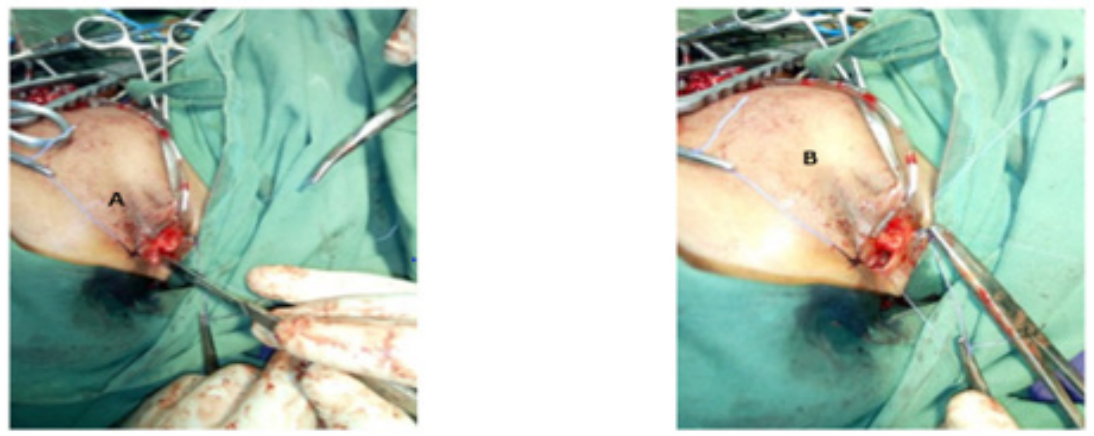

Figure 3: Multilayer repair of the urethrovaginal fistula.

Peri vesical tissue(a) were mobilized for the final multilayer repair(b).

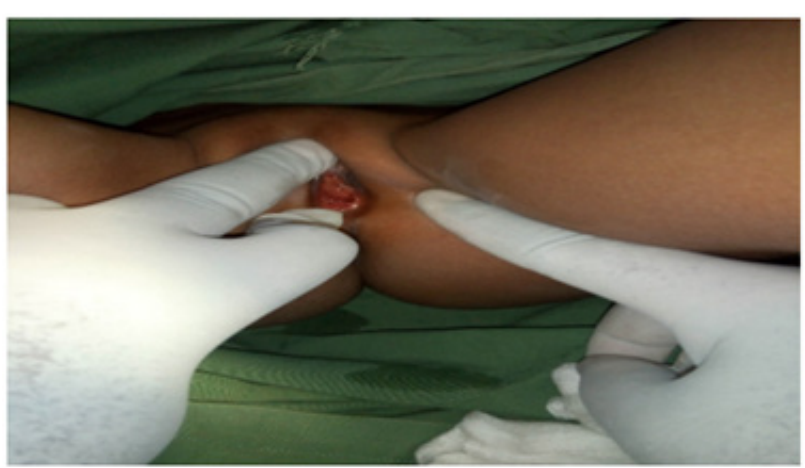

Figure 4: Post-operative picture of the vulva showing normal urethra and vagina.

\section{Discussion}

Urethrovaginal fistula is an abnormal tract lined by epithelium connecting urethra and vagina. In children it can be congenital or post traumatic $[1,2]$. Female genital mutilation is an important aetiology in Sub-Saharan Africa [3,4]. Female genital mutilation describes socio-cultural practices that manipulate, alter or remove female external organs in young girls and women for non-medical reasons [7]. Is common in Sub-Saharan Africa and is culturally believe to prepare girls for adulthood and marriage $[5,7]$. It associated with short term and long terms complications which include bleeding, pain, infections, urinary, gynecological and obstetric complications [4,5,7]. Urogynaecological complications include that of urethrovaginal and vesicovaginal fistulae [2-4].

Our patients had history of FGM with is consistent with what was reported by Kiosoglous, et al. [2], Webster, et al. [3], Meeks, et al. [4], and Coulibaly et al [11]. They reported that urethrovaginal fistula in girls can be congenital or post traumatic. Female genital mutilation is high among Nigerian women but the prevalence is declining in girls [5]. The age of patients of 12 years is higher than the average age reported for FGM of 5-8 years [7]. Coulibaly and Sangare [11]reported 5-year-old girl with urethrovaginal fistula which was suspected to be post traumatic as the traumatic event was not obvious.

The index patient presented with inability to pass urine through the urethra which is contrary to the findings in literature that Urethrovaginal fistula present with involuntary loss of urine $[1,2,4]$. But the leakage of the urine varies with the size of the fistula and the position of the patient [1]. It may be asymptomatic or present with mild urinary discharge in small fistula that is high up in the bladder [2,3]. Absence of urinary incontinence in this patient is due to involvement of the bladder neck and subsequently complete obliteration of the lumen due healing by fibrosis. 
The diagnosis of the fistula was difficult as clinical examination was difficult in girls as reported by Coulibaly and Sangare [11]. The diagnosis was established following examination under anaesthesia [11]. Micturating cystourethrogram was not helpful due to the presence of bladder outlet obstruction. But the main stay of diagnosis is imaging studies $[1,11,12]$ such as micturating cystogram with or without lateral progression which will demonstrate the fistulous tract and opacification vagina super imposed on the bladder. Multilayer repair was achieved with peri vaginal and peri vesical tissue as reported by Wesbster [3], Coulibaly [11] and Pusharkar [13] . This has been reported to be difficult $[3,13]$ as observed in the index case. Our approach was abdominoperineal approach as the defect was mid-urethral and associated with obliteration of the bladder neck. This is similar to what was reported by Coulibaly and Sangare [11] in Abidjan, Cote d'Ivoire. The management of urethrovaginal fistula in children is associated with urinary incontinence due to sphincteric damage $[3,11,13]$. There was no incontinence in our patient but we encountered enuresis which was managed with anticholinergics. And no features of stress urinary incontinence.

\section{Conclusion}

Urethrovaginal fistula from female genital mutilation may present with bladder outlet obstruction. Micturating cystogram may not be diagnostic. Examination under anaesthesia may be necessary for proper diagnosis. Abdominoperineal multilayer repair is associated with good outcome.

\section{Acknowledgement}

None.

\section{Conflict of Interest}

No conflict of interest.

\section{References}

1. Badlani GH, Dirk JMK, De Ridder DJMK, Mettu RJ, Rovner ES (2016) Urinary fistula. In: Wein AJ, Kavoussi LR, Partin AW, Peters CA, editors.
Campbell -Walsh's Urology. (11 ${ }^{\text {th }}$ edn), Philadelphia, USA, pp.60696162.

2. Kiosoglous AJ, Greenwell TJ (2015) Vesico-vaginal and urethro-vaginal fistulae in the developed world. Journal of Clinical Urology 8(4): 233239.

3. Webster GD, Sihelnik SA, Stone AR (1984) Urethrovaginal Fistula: A Review of the Surgical Management. The Journal of Urology 132(3): 460-462.

4. Meeks G, Ghafar M (2012) Vesicovaginal and Urethrovaginal Fistulas. Glob libr women's med.

5. Okeke TC, Anyaehie U, Ezenyeaku C (2012) An overview of female genital mutilation in Nigeria. Ann Med Health Sci Res 2(1): 70-73.

6. World Health Organization (2020) Female Genital Mutilation.

7. Klein E, Helzner E, Shayowitz M, Kohlhoff S, Smith-Norowitz TA (2018) Female Genital Mutilation: Health Consequences and Complications-A Short Literature Review. Hindawi Obstetrics and Gynecology International : 1-7.

8. Karmaker B, Kandala NB, Chung D, Clarke A (2011) Factors associated with female genital mutilation in Burkina Faso and its policy implications. Int J Equity Health 10: 20.

9. Setegn T, Lakew Y, Deribe K (2016) Geographic Variation and Factors Associated with Female Genital Mutilation among Reproductive Age Women in Ethiopia: A National Population Based Survey. Plos One 11(1): e0145329.

10. Sakeah E, Debpuur C, Oduro AR , Welaga P , Aborigo R, et al. (2018) Prevalence and factors associated with female genital mutilation among women of reproductive age in the Bawku municipality and Pusiga District of northern Ghana. BMC Women's Health 18(1): 150.

11. Coulibaly N, Sangaré IS (2015) Urethrovaginal Fistula in a 5-Year-Old Girl. Case Reports in Urology: 1-4.

12. Nam C Yu, Steven S Raman, Monica Patel, Zoran Barbaric (2004) Fistulas of the Genitourinary Tract: A Radiologic Review. Radio Graphics 24(5).

13. Pusharkar DY, Dyakov VV, Kosko JW, Kasyan GR (2006) Management of urethrovaginal fistula. European Urology 50(5): 1000-1005. 